DETERMINAÇÃO QUANTITATIVA DE NITRATO E NITRITO EM SALAMES TIPO ITALIANOS COMERCIALIZADOS NA REGIÃO DE COLOMBO - PARANÁ.

\title{
QUANTITATIVE DETERMINATION OF NITRATE AND NITRITE CURED SALTS IN ITALIAN TYPE SALAMIS SAUSAGES SOLD IN COLOMBO CITY - PARANÁ.
}

\author{
ROSA, Tacianny Alves Moraes ${ }^{1 *}$ DEGÁSPARI, Cláudia Helena ${ }^{2}$ \\ 1-Discente do Curso de Farmácia das Faculdades Integradas do Brasil - UniBrasil \\ E-mail: tacianny_lp@yahoo.com.br \\ 2-Professora Colaboradora das Faculdades Integradas do Brasil - UniBrasil \\ E-mail: sensus @cwb.matrix.com.br
}

\section{RESUMO:}

Os nitritos e nitratos estão presentes em sais de cura e possuem função conservante, tendo sua principal ação contra a bactéria Clostridium botulinum, por isso são normalmente utilizado em embutidos, como o salame italiano. No entanto, a exposição contínua do ser humano a nitratos $\left(\mathrm{NO}_{3}^{-}\right)$e nitritos $\left(\mathrm{NO}_{2}{ }^{-}\right)$pode levar a formação de nitrosaminas, que possuem caráter carcinogênico. A legislação brasileira limita a utilização destes conservantes em $0,03 \mathrm{~g} / 100 \mathrm{~g}$ para nitrato e $0,015 \mathrm{~g} / 100 \mathrm{~g}$ para nitrito. Com o objetivo de analisar quantitativamente os níveis de nitrato e nitrito em quatro marcas de salames tipo italiano comercializadas na cidade de Colombo - Paraná, observou-se que os resultados demonstram que as quatro marcas analisadas encontravam-se com teores permitidos pela legislação vigente. Com relação à análise dos rótulos dos produtos, detectaram-se não conformidades quanto à comercialização de produtos sem registro sanitário, bem como de produtos com restrição de comercialização (que apresentam registros sanitários SIM ou SIE de outras regiões), e, portanto, sendo comercializados irregularmente nesta cidade.

PALAVRAS-CHAVE: salame, teor nitrato, teor nitrito, registros sanitários.

\section{ABSTRACT:}

Nitrates and nitrites salts are present in cure meat products and have a conservative function, mainly against the bacterium Clostridium botulinum. They are usually used in cured sausage and meat, as the Italian salami sausage. However, people consume nitrates $\left(\mathrm{NO}_{3}{ }^{-}\right)$and nitrites $\left(\mathrm{NO}_{2}{ }^{-}\right)$daily, and these cured salts may transform themselves into nitrosamines, that are potentially carcinogenic to human race. The Brazilian laws limit the use of these conservatives' substances in $0,03 \mathrm{~g} / 100 \mathrm{~g}$ for nitrate and $0,015 \mathrm{~g} / 100 \mathrm{~g}$ for nitrite. In order to analyze quantitatively the levels of nitrate and nitrite in four brands of Italian type salami commercialized in the city of Colombo - Paraná, it was observed that the results show that the four brands tested were at levels allowed by law. The labels analysis of these four products detected no conformities like products without 
sanitary health registration, as well as of products with commercialization restriction (only could be marked in a restrictive state or city, not in another and wherever place). Therefore, they are being marketed irregularly in this city.

KEY WORDS: cured salami sausage, nitrate quantity, nitrite quantity, sanitary health registration.

\section{INTRODUÇÃO}

De acordo com a Instrução Normativa $n^{\circ} 22$ de 31 de julho de 2000 do Ministério da Agricultura, Pecuária e do Abastecimento o salame italiano é: um produto cárneo, elaborado de carnes unicamente suínas ou suínas e bovinas conjuntamente, além de toucinho, adicionado de outros ingredientes, com toda a massa moída em granulometria média entre 6 e $9 \mathrm{~mm}$, embutido em envoltórios naturais ou artificiais, curado, defumado ou não, fermentado, maturado e dessecado por tempo indicado pelo processo de fabricação (BRASIL, 2000).

Dentre os sais de cura, destacam-se os sais de nitrato e de nitrito de sódio. Sua função é a de inibir crescimento de algumas bactérias, especialmente o Clostridium botulinum, retardar o desenvolvimento da rancificação, além de conferir sabor e o tom avermelhado característico (ORDÓÑEZ et al, 2005).

No entanto, deve-se levar em consideração que o uso de sais de nitrato e nitrito deve seguir a legislação vigente, já que seu uso indiscriminado pode acarretar sérios danos à saúde de seus consumidores. De acordo com ORDOÑEZ e colaboradores (2005) os altos teores residuais de sais de nitrato ou nitrito em alimentos protéicos podem levar ao surgimento de nitrosaminas que são comprovadamente cancerígenas. Quedas rápidas de $\mathrm{pH}$ na fabricação do salame, podem interferir no processo químico de oxi-redução dos sais de nitrato para sais nitrito, levando a um aumento da possível formação de nitrosaminas, que, como citado anteriormente, apresentam grande potencial carcinogênico (TERRA, 2006).

De acordo com o descrito nas legislações específicas para o uso de sais de nitrato e nitrito em produtos, seu emprego é permitido em quantidades mínimas, ou seja, em partes por milhão (ppm), o que significa que a dosagem aplicada dependendo da quantidade a ser produzida, dificilmente pode ser precisamente mensurada em balanças de uso doméstico ou com pouco grau de precisão, pois pode levar ao erro por excesso (conduzindo a toxicidade dos produtos finais) ou ao erro pela escassez (conduzindo ao risco de grave contaminação e desenvolvimento de microbiota com alto risco de patogenicidade) (TERRA, 2006).

Desta forma, não desmerecendo todo esforço e mérito do trabalho de agroindústrias, o perigo de se fornecer produtos embutidos com problemas de seguridade alimentar à população pode estar presente e não deve ser negligenciado 
sendo que o monitoramento de tais produtos artesanais, bem como dos produzidos em larga escala por indústrias de médio e grande porte, deveria ser uma constante por parte de órgãos fiscalizadores.

\section{OBJETIVOS}

Este trabalho foi idealizado devido ao fato de que na região de Colombo-PR, há uma rota turística denominada "Circuito Italiano de Turismo Rural", onde diversas pequenas propriedades rurais produzem alimentos de forma artesanal e os revendem aos turistas. Assim, foram coletadas amostras de salames comercializados na região da cidade de Colombo - PR em pontos de venda como mercados e feiras de alimentos, realizando quantitativamente o teor de sais de nitrato e nitrito, por meio de testes de espectrofotometria nos laboratórios das Faculdades Integradas do Brasil - UniBrasil, de forma a obter-se informações importantes quanto ao nível de seguridade alimentar destes produtos com base no estabelecido na legislação vigente, analisando ainda os aspectos sensoriais das amostras através de análise sensorial descritiva utilizando-se dos termos descritivos para produtos cárneos curados, bem como os dados de rotulagem, observando se os mesmos possuem o Serviço de Inspeção Intramunicipal (SIM) e Serviço de Inspeção Intraestadual (SIE).

\section{REVISÃO DE LITERATURA}

\subsection{O emprego de sais de nitrato e nitrito}

Sais de cura como o nitrato e o nitrito de sódio ou potássio são amplamente utilizados no processamento de embutidos cárneos como aditivos alimentares. Esses sais conservam a carne contra a deterioração bacteriana, são fixadores de cor e agentes de cura (OLIVEIRA; ARAUJO; BORGO, 2005). Os nitritos fixam mais rapidamente a cor, sendo empregados em menor quantidade que o nitrato (ORDÓÑEZ etal., 2005).

As concentrações de nitrato e/ou nitrito acima do permitido pela legislação podem acarretar sérios riscos à saúde dos consumidores, visto que o íon nitrito pode reagir com aminas e amidas do meio, e originar nitrosaminas e nitrosamidas, que atuam como carcinógenos para o homem e ainda, uma vez ingeridos por crianças, o nitrito pode agir sobre as hemoglobinas o que leva ao processo de metahemoglobinemia, que impede a função normal de transporte de oxigênio. A recomendação é reduzir a adição desses aditivos à quantidade mínima possível para que exerça suas funções (SOUZA; FALEIROS; SOUZA, 1990; ORDÓÑEZ et al., 2005)

Os nitratos e/ou nitritos possuem ainda efeito inibidor específico para bactérias. 
O desenvolvimento de algumas espécies de microorganismos causadores de toxinfecções como o Clostridium botulinum, Salmonella ssp e Staphylococcus ssp são inibidos em concentrações de nitritos de 80 a $150 \mathrm{mg} / \mathrm{kg}$ (ORDÓÑEZ et al., 2005)

O uso do nitrato é permitido em até $0,03 \mathrm{~g} / 100 \mathrm{~g}$ de carne e o uso de nitrito em até $0,015 \mathrm{~g} / 100 \mathrm{~g}$ de carne de acordo com a Portaria $\mathrm{n}^{0} 1.004$ de 11 de dezembro de 1998 da Secretaria de Vigilância Sanitária do Ministério da Saúde, que aprova o uso destes aditivos. $\mathrm{O}$ uso do nitrato e/ou nitrito dentro dos parâmetros desta legislação, não são prejudiciais à saúde, e são relativamente importantes, pois protegem o salame contra microrganismos causadores de toxinfecções, além conferir a cor característica deste alimento (BRASIL, 1998).

O emprego destes aditivos parece não aumentar significativamente os riscos de câncer, quando empregados nas quantidades limites especificadas em legislação. Nestas condições sua contribuição para os níveis globais de lesão do DNA é pequena. Assim sendo, cabe ponderar que o risco potencial à saúde devido a alimentos contaminados microbiologicamente é muito mais grave, se esses conservantes não forem usados nos níveis adequados e especificados por lei (LEHNINGER; NELSON; COX, 2000; VOET; VOET; PRATT, 2000).

\subsection{0 desenvolvimento do botulismo}

De acordo com o Guia de Vigilância Epidemiológica da Secretaria de Vigilância em Saúde do Ministério da Saúde, o botulismo é uma doença neuroparalítica grave, não contagiosa onde é induzida por uma potente toxina produzida pela bactéria Clostridium botulinum, um bacilo gram-positivo, anaeróbio, esporulado, sendo que a sua forma vegetativa produz oito tipo de toxinas e um dos reservatórios dos esporos é o intestino de mamíferos. Existem três formas de ocorrência de botulismo, sendo elas pelas vias: alimentar, por ferimento ou ainda intestinal, onde todas essas formas se caracterizam por manifestações neurológicas e/ou gastrointestinais. A transmissão do botulismo alimentar ocorre por ingestão da toxina em alimentos previamente contaminados, seja por produção ou conservação inadequadas. Os principais sintomas são gastrointestinais (náuseas, vômitos, diarréias e dor abdominal) e neurológicos (cefaléia, vertigem e tontura). Com a evolução da doença, a fraqueza muscular e insuficiência respiratória, podem agravar o quadro e até mesmo levar a óbito Quando sua causa é por alimentos contaminados, deve-se fazer uma notificação epidemiológica, pois um caso suspeito é considerado surto e emergência de saúde pública (BRASIL, 2009). 


\section{METODOLOGIA}

\subsection{Coleta das amostras}

O processo de coleta das 4 (quatro) amostras foi realizado entre os dias 29 de agosto e 5 de setembro de 2013 em mercados e feira de rua sem um levantamento ou controle estatístico representativo, pois este não era o foco do trabalho, devido ao exímio tempo disponível e ao grau de complexidade envolvida, bem como os custos resultantes. As amostras foram então coletadas de forma casualística, todas em uma mesma semana, buscando com isso, a possibilidade ou probabilidade de determinação de uma falha de processo ou de formulação ou de não conformidade legal.

Foram feitas dosagens de sais de nitrato e de nitrito em salames do tipo italiano vendidos na região de Colombo - Paraná, utilizando quatro amostras de diferentes produtores. Foi realizada ainda uma análise sensorial descritiva das amostras empregando-se os termos descritivos para carne curada.

As amostras foram codificadas neste trabalho (a título de manutenção da privacidade dos fabricantes) como amostras $A, B, C$ e D, sendo a amostra $A$ representada por um produto do "tipo fabricação artesanal".

\subsection{Determinação dos teores de nitrato e nitrito}

Os reagentes utilizados foram disponibilizados pelas Faculdades Integradas do Brasil - UniBrasil, juntamente com as vidrarias e aparelhos de espectrofotometria de varredura da marca Quimis Q798U2VS, centrífuga para tubos Centribio 80-2B, balança analítica Quimis Q500L210C e banho-maria Quimis Q-334-18.

De acordo com a técnica descrita em Mantovani (2005), realizou-se quantificação direta dos sais de nitrato presentes nas amostras através da nitração do ácido salicílico em meio ácido com formação de um composto colorido, com posterior leitura em comprimento de onda de $410 \mathrm{~nm}$ em aparelho espectrofotômetro de espectro visível e ultravioleta. Já para a dosagem de nitrito ocorre a diazotação de nitritos com ácido sulfanílico e conjugada com cloridrato de alfa-naftilamina em meio ácido, formando o ácido alfa-naftilamino-p-azobenzeno-p-sulfônico de coloração rósea. 0 produto resultante é determinado com leitura em comprimento de onda de $540 \mathrm{~nm}$ em espectrofotômetro de espectro visível e ultravioleta.

Os teores de nitrato e nitrito das quatro amostras foram determinados pela construção de curvas padrão distintas para ambos composto e, a partir do método de regressão linear por métodos gráfico e equação da reta, gerados pelo software planilha Excel@, onde se obteve os valores relativos destes aditivos nas amostras. Todas as análises foram feitas em duplicatas. 


\subsection{Análise sensorial descritiva}

As análises sensoriais das quatro amostras foram realizadas por quatro degustadores treinados e conhecedores dos termos descritivos para produtos cárneos liderados por uma das autoras deste trabalho (DEGÁSPARI, 2013). A degustação foi realizada às cegas (sem conhecimento prévio de qualquer caracterização das amostras coletadas), onde a outra autora deste trabalho (ROSA) preparou as quatro amostras em recipientes individuais, codificados com três dígitos e a degustação realizada no Laboratório de Técnicas Dietéticas e Análise Sensorial das Faculdades Integradas do Brasil - UniBrasil no método de mesa redonda.

\section{RESULTADOS E DISCUSSÃO}

As quatro amostras foram primeiramente analisadas com relação aos dados disponíveis nos dizeres de rotulagem referentes às questões dos respectivos registros sanitários. O produto codificado com marca A não apresentou um CNPJ tampouco um registro sanitário (nem mesmo um SIM) em seu rótulo. O produto codificado com a marca B possuía um registro SIE-PR, estando este dentro das conformidades legais esperadas, uma vez que a cidade em questão encontra-se sob a jurisdição do Estado do Paraná. No entanto, o produto codificado com a marca $\mathrm{C}$ apresentou um registro SIM, porém de um outro município distante de $46 \mathrm{~km}$ (por estrada) do local de comercialização (município de Campo Largo - PR). Já o produto codificado com a marca D, apresentou um registro SIE, porém do Estado de Santa Catarina. Esta simples amostragem se mostra preocupante, pois a legislação referente aos registros sanitários de restrição de comercialização, não estão sendo respeitadas em três dentre as quatro marcas analisadas ( $75 \%$ ) e estão sendo vendidas de forma irregular.

Os resultados da análise sensorial descritiva, utilizando-se os termos descritivos para produtos cárneos curados, para as quatro amostras encontram-se no QUADRO 01. 
QUADRO 01 -ANÁLISE SENSORIAL DESCRITIVADAS AMOSTRAS.

\begin{tabular}{|c|c|c|c|c|}
\hline $\begin{array}{l}\text { ATRIBUTOS } \\
\text { SENSORIAIS }\end{array}$ & MARCA A & MARCA B & MARCA C & MARCA D \\
\hline APARÊNCIA & $\begin{array}{l}\text { Alto teor de } \\
\text { umidade o que } \\
\text { torna a peça } \\
\text { muito maleável. } \\
\text { Menor agregação } \\
\text { das partículas } \\
\text { com uma } \\
\text { granulometria } \\
\text { muito fina/moída. }\end{array}$ & $\begin{array}{c}\text { Granulometria } \\
\text { fina, porém as } \\
\text { partículas } \\
\text { apresentam-se } \\
\text { agregadas, } \\
\text { formando uma } \\
\text { película ao redor } \\
\text { da peça, que lhe } \\
\text { dá formato. } \\
\text { Parece ser } \\
\text { fibroso. }\end{array}$ & $\begin{array}{c}\text { Produto firme, } \\
\text { com } \\
\text { granulometria } \\
\text { uniforme, } \\
\text { permitindo a } \\
\text { manutenção do } \\
\text { formato da peça. }\end{array}$ & $\begin{array}{l}\text { Partículas } \\
\text { uniformes e } \\
\text { agregadas, } \\
\text { apresentando-se } \\
\text { distribuídas de } \\
\text { forma circular no } \\
\text { interior da peça. }\end{array}$ \\
\hline GOSTO & $\begin{array}{l}\text { Gosto metálico } \\
\text { pronunciado. } \\
\text { Gorduroso. Alto } \\
\text { amargor. Gosto } \\
\text { ácido mediano. }\end{array}$ & $\begin{array}{l}\text { Extremamente } \\
\text { ácido e levemente } \\
\text { adocicado. } \\
\text { Ausência de } \\
\text { sabor metálico. }\end{array}$ & $\begin{array}{l}\text { Extremamente } \\
\text { salgado, leve } \\
\text { sabor metálico, } \\
\text { não adocicado e } \\
\text { acidez mediana. }\end{array}$ & $\begin{array}{l}\text { Gosto salgado } \\
\text { imperceptível, } \\
\text { acidez } \\
\text { baixíssima, e } \\
\text { sabor metálico } \\
\text { pronunciado. }\end{array}$ \\
\hline SABOR & $\begin{array}{l}\text { Sabor cárneo } \\
\text { inexpressível. } \\
\text { Aparente baixa } \\
\text { cura. Sabor de } \\
\text { defumado } \\
\text { agradável e } \\
\text { suave. }\end{array}$ & $\begin{array}{l}\text { Sabor cárneo } \\
\text { agradável e bem } \\
\text { característico a } \\
\text { carne suína. } \\
\text { Sabor de fumaça } \\
\text { bem pronunciado. }\end{array}$ & $\begin{array}{c}\text { Sabor cárneo } \\
\text { pouco } \\
\text { pronunciado. } \\
\text { Sabor de fumaça } \\
\text { pouco } \\
\text { pronunciado. } \\
\text { Levemente } \\
\text { apimentado. }\end{array}$ & $\begin{array}{c}\text { Sabor cárneo } \\
\text { pouco } \\
\text { pronunciado. } \\
\text { Sabor de fumaça } \\
\text { ausente. }\end{array}$ \\
\hline TEXTURA & $\begin{array}{l}\text { Desintegra muito } \\
\text { facilmente na } \\
\text { mastigação, com } \\
\text { alta quantidade } \\
\text { de cartilagem e a } \\
\text { carne muito } \\
\text { macia. }\end{array}$ & $\begin{array}{l}\text { Textura cárnea } \\
\text { irregular, mas } \\
\text { ausente de } \\
\text { cartilagem. }\end{array}$ & $\begin{array}{c}\text { Textura com } \\
\text { mastigação muito } \\
\text { satisfatória e com } \\
\text { ausência de } \\
\text { cartilagens. }\end{array}$ & $\begin{array}{c}\text { Textura cárnea } \\
\text { muito fina, } \\
\text { encobrindo o } \\
\text { sabor da gordura, } \\
\text { que se apresenta } \\
\text { também } \\
\text { finamente moída. }\end{array}$ \\
\hline $\begin{array}{c}\text { PARECER } \\
\text { SENSORIAL } \\
\text { FINAL }\end{array}$ & $\begin{array}{l}\text { Característico de } \\
\text { produto cru e sem } \\
\text { processo de cura } \\
\text { adequado. } \\
\text { Propriedades } \\
\text { sensoriais que } \\
\text { não transmitem } \\
\text { segurança } \\
\text { infecto- } \\
\text { toxicológica. }\end{array}$ & $\begin{array}{l}\text { Produto com } \\
\text { características } \\
\text { sensoriais muito } \\
\text { harmônicas } \\
\text { adequadas para } \\
\text { fins de } \\
\text { comercialização }\end{array}$ & $\begin{array}{l}\text { Produto com boas } \\
\text { características } \\
\text { sensoriais e } \\
\text { adequadas para } \\
\text { fins de } \\
\text { comercialização. }\end{array}$ & $\begin{array}{l}\text { Produto sem } \\
\text { identidade } \\
\text { sensorial. }\end{array}$ \\
\hline
\end{tabular}

De acordo com o relatado no QUADRO 01, a amostra B foi a que apresentou as características sensoriais mais adequadas e harmônicas. Por outro lado, a amostra D apresentou-se sensorialmente inadequada sem uma identidade sensorial característica para um produto tipo "salame".

Os teores de nitrato, nitrito e $\mathrm{pH}$ das 4 amostras encontram-se relacionados no QUADRO 02 e foram obtidos a partir das curvas padrão com regressão linear apresentadas nas FIGURAS 01 e 02. 
FIGURA 01 - CURVA PADRÃO E REGRESSÃO LINEAR UTILIZADAS PARA DETERMINAÇÃO DOS TEORES DE NITRATO DASAMOSTRAS.

\section{Curva Padrão de Nitrato}

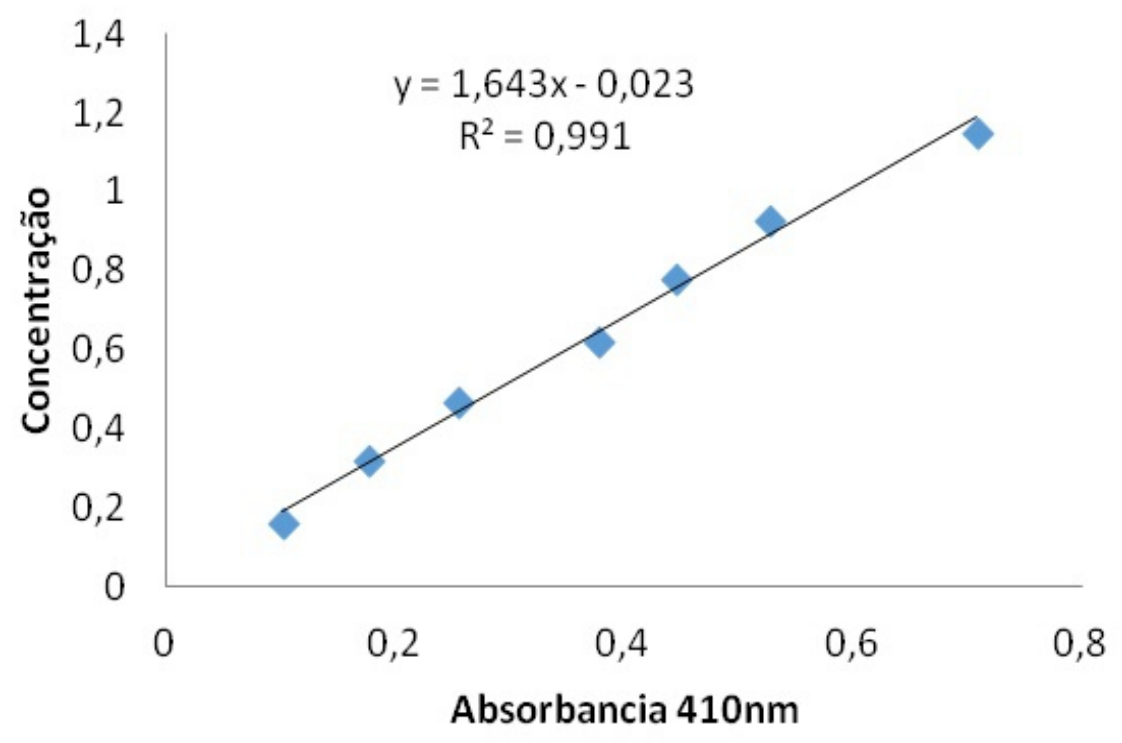

FIGURA 02 - CURVA PADRÃO E REGRESSÃO LINEAR UTILIZADAS PARA DETERMINAÇÃO DOS TEORES DE NITRITO DASAMOSTRAS.

\section{Curva Padrão de Nitrito}

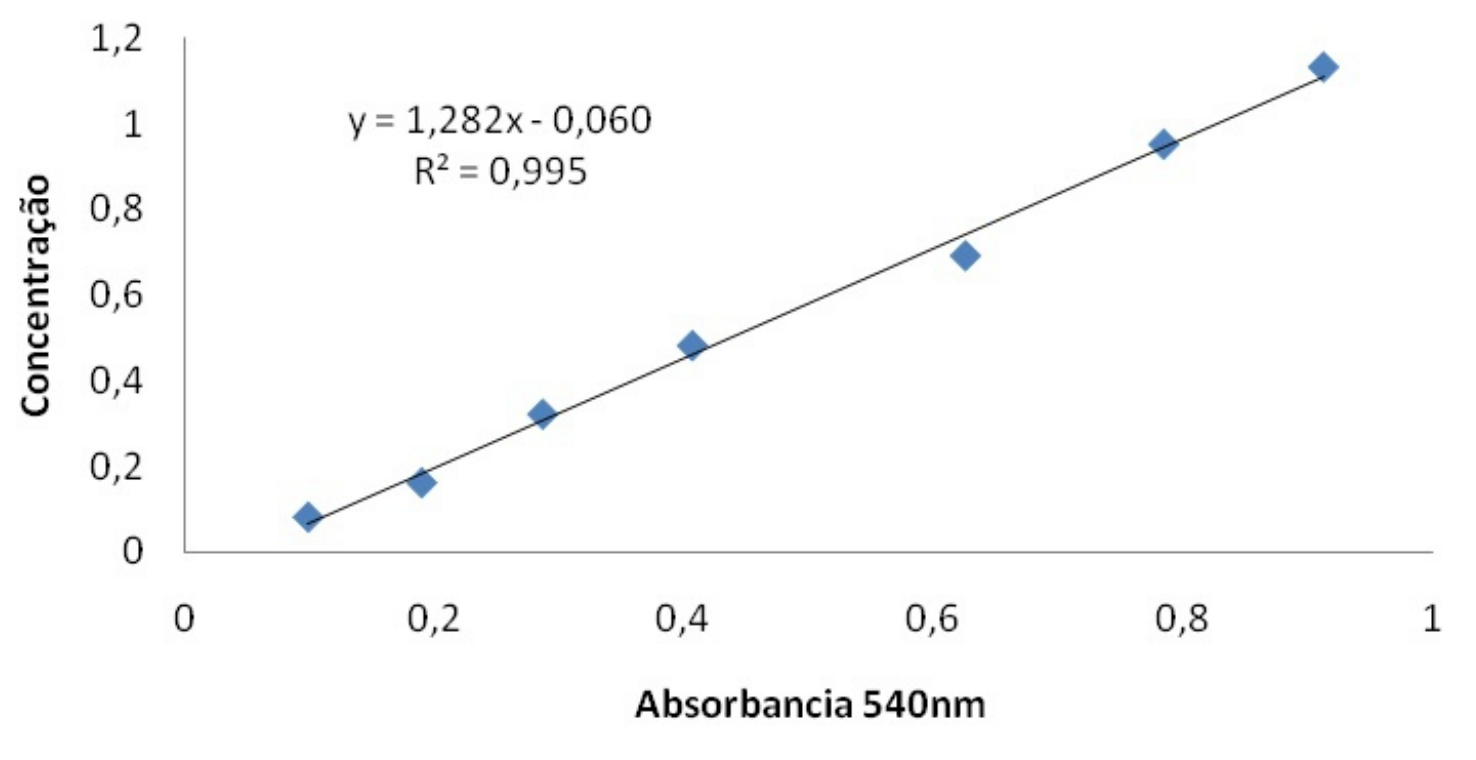


QUADRO 02 - VALORES DETERMINADOS DE pH, NITRATO E NITRITO PARAAS QUATROAMOSTRASANALISADAS.

\begin{tabular}{c|c|c|c}
\hline $\begin{array}{c}\text { Marcas } \\
\text { Codificadas dos } \\
\text { Salames }\end{array}$ & $\begin{array}{c}\text { Valores de } \\
\mathrm{pH}\end{array}$ & $\begin{array}{c}\text { Teores de Nitrato } \\
\text { Determinados } \\
\text { (até 300mg/kg) }\end{array}$ & $\begin{array}{c}\text { Teores de Nitrito } \\
\text { Determinados } \\
\text { (até 150mg/kg) }\end{array}$ \\
\hline A & 5,31 & 285,36 & 66,45 \\
\hline B & 5,35 & 181,70 & 65,99 \\
\hline C & 5,28 & 159,75 & 54,76 \\
\hline D & 6,07 & 104,87 & 60,06 \\
\hline
\end{tabular}

Com os resultados apresentados, verificou-se que a quantidade de nitrato presente na amostra A de 285,36 mg/kg é maior do que nas demais amostras, porém quase atingindo o valor máximo permitido que é de $300 \mathrm{mg} / \mathrm{kg}$, que pode ter acarretado o desagradável sabor metálico pronunciado detectado sensorialmente.

Com relação aos teores de nitrato, observou-se que a amostra $\mathrm{D}$, o valor de nitrato é o menor apresentado (104,87 mg/kg), o que, possivelmente levou-o a apresentar-se sem uma identidade sensorial adequada. Da mesma forma, o valor de nitrito da marca A apresentam-se acima das demais, mas ainda encontra-se dentro do permitido pela legislação que é de $150 \mathrm{mg} / \mathrm{kg}$ com 66,45 mg/kg. Já a amostra C foi a que apresentou a menor quantidade de nitrito, com $54,76 \mathrm{mg} / \mathrm{kg}$.

Quantos aos valores de pH, de acordo com MARTINS (2006), a estabilidade do pigmento cárneo (mioglobina) de embutidos é influenciada pelo $\mathrm{pH}$ e pelo potencial redox. Quanto mais baixo de 6,0 estiver o pH menor será a estabilidade do pigmento. Por isso, é importante utilizar na formulação tecido gorduroso fresco e excluir o máximo possível de oxigênio na massa. No caso das quatro amostras analisadas, a que apresenta esta característica adequada de $\mathrm{pH}$ e, portanto, resultará numa estabilidade da cor mais estendida é a amostra D que é proveniente do Estado de Santa Catarina. Porém, este aumento no valor do $\mathrm{pH}$ comparativamente com os demais produtos, conferiu-Ihe características sensoriais desagradáveis, tendo sido percebido seu baixo nível de acidez o que the valeu o parecer final sensorial de "sem identidade". Assim, há de se analisar qual dos parâmetros sensoriais: cor ou gosto/sabor se deseja salientar no produto. No caso do produto salame, a característica ácida é considerada um padrão de qualidade sensorial característico e imprescindível.

\section{CONSIDERAÇÕES FINAIS}

Verificando os valores encontrados de nitrato e nitrito, percebeu-se que estes não se encontram acima dos valores permitidos pela legislação, mesmo para a amostra 
A, que é a de fabricação "tipo fabricação artesanal", estando ligeiramente acima das demais amostras, mas ainda está dentro do valor legalmente permitido. Isso mostra que, nestes quatro amostras coletadas, houve um cuidado e atenção quanto ao emprego desses aditivos nos produtos e que o produto artesanal e os outros três produtos industrializados estão atentos às recomendações do emprego desses conservantes.

No entanto, os autores levantam uma questão de que, a legislação indica a quantidade máxima a ser aplicada, porém nada cita ou especifica a respeito da quantidade mínima desses conservantes para que estes tenham ação eficaz. A despeito do que se pode imaginar, o valor mínimo também é de suma importância pois, enquanto o máximo previne aspectos voltados à parte toxicológica, o valor mínimo está diretamente ligado aos aspectos de toxicoinfecções, tão ou mais grave que o anterior.

Outro dado preocupante diz respeito à comercialização de produtos sem registro sanitário, bem como de produtos com restrição de comercialização (que apresentam registros sanitários SIM ou SIE), e, portanto, irregulares legalmente, cabendo aos órgãos competentes uma maior atenção na fiscalização dos mesmos.

\section{REFERÊNCIAS}

BRASIL. Agência Nacional de Vigilância Sanitária.Secretaria de Vigilância Sanitária. Atribuição de Função de Aditivos, Aditivos e seus Limites máximos de uso para a Categoria 8 - Carne e Produtos Cárneos. Portaria n 1.004, de 11 de dezembro de 1998. Disponível em: http://www.mrconsultoriaemalimentos.com.br/pdf/PORTARIA_N _1004.pdf. Acesso em: 19 maio de 2013.

BRASIL. Ministério da Saúde. Secretaria de Vigilância em Saúde. Departamento de Vigilância Epidemiológica. Guia de vigilância epidemiológica / Ministério da Saúde, Secretaria de Vigilância em Saúde, Departamento de Vigilância Epidemiológica. 7 ed. Brasília: Ministério da Saúde, 2009. Disponível em: <http://portal.saude.gov.br/portal/arquivos/pdf/gve_7ed_web_atual_botulismo.pdf> Acesso em: 19 setembro de 2013.

BRASIL. Ministério da Agricultura. Secretaria de Defesa Agropecuária. Regulamento Técnico de Identidade e Qualidade do Salame Tipo Italiano. Instrução Normativa No 22 , de 31 de Julho de 2000 . D isponível e m: $<$ http://sistemasweb.agricultura.gov.br/sislegis/action/detalhaAto.do?method=consult arLegislacaoFederal> Acesso em: 20 maio de 2013.

DEGÁSPARI, C.H. Análise Sensorial Aplicada à Gastronomia, à Área da Saúde e 
às Engenharias. Rio de Janeiro: Fundação Biblioteca Nacional. 2013. Registro de Direitos Autorais $n^{\circ} 596.258$.

LEHNINGER, A.L.; NELSON,D.L.; COX,M.M., Princípios de Bioquímica. 2.ed. São Paulo: Sarvier. 2000.

MANTOVANI, J.R.; CRUZ, M.C.P. FERREIRA, M.E.F.; BARBOSA, J.C. Comparação de procedimentos de quantificação de nitrato em tecido vegetal. Pesq. Agropec. Bras. v.40, n.1, p. 53-59, 2005.

MARTINS, R. Produção de Embutidos Crus-Curados (Salame). Rio de Janeiro: REDETEC Rede de Tecnologia do Rio de Janeiro, 2006.

OLIVEIRA, M. J.; ARAUJO, W.M.C.; BORGO L.A., Quantificação de Nitrato e Nitrito em Linguiças do Tipo Frescal. Ciênc. Tecnol. Aliment., Campinas, v.25, n.4, p. 736-742, o u t . - d e z. $\quad 2005$ Dis ponível e m : <http://repositorio.bce.unb.br/bitstream/10482/8171/1/ARTIGO_QuantificacaoNitrato Nitrito.pdf>. Acesso em 22.05.2013

ORDÓÑEZ, J. et al. Tecnologia de alimentos - Origem animal. Porto Alegre: Artmed, 2005.

SOUZA, P.A.; FALEIROS, R.R.S; SOUZA, H.B.A. Dosagem de Nitrato e Nitrito em Produtos Embutidos de Carne. Alim. Nutri. São Paulo. 1990. Disponível em: <http://200.145.71.150/seer/index.php/alimentos/article/view/684/575>. Acesso em: 19 abr. de 2013.

TERRA, N.N.; SHIMOKOMAKI, M.; FRANCO, B.D.G.M. Atualidades em Ciências e Tecnologia de Carnes. São Paulo: Varela, 2006.

VOET, D.; VOET,J.G.; PRATT,C.W., Fundamentos de Bioquímica. Porto Alegre: Artes Médicas. 2000. 